\title{
Barriers and opportunities of combining social and ecological functions of urban greenspaces - Users' and landscape professionals' perspectives
}

DOI:

10.1016/j.ufug.2019.02.007

\section{Document Version}

Accepted author manuscript

Link to publication record in Manchester Research Explorer

Citation for published version (APA):

Shams, I., \& Barker, A. (2019). Barriers and opportunities of combining social and ecological functions of urban greenspaces - Users' and landscape professionals' perspectives. Urban Forestry and Urban Greening, 39, 67-78. https://doi.org/10.1016/j.ufug.2019.02.007

Published in:

Urban Forestry and Urban Greening

\section{Citing this paper}

Please note that where the full-text provided on Manchester Research Explorer is the Author Accepted Manuscript or Proof version this may differ from the final Published version. If citing, it is advised that you check and use the publisher's definitive version.

\section{General rights}

Copyright and moral rights for the publications made accessible in the Research Explorer are retained by the authors and/or other copyright owners and it is a condition of accessing publications that users recognise and abide by the legal requirements associated with these rights.

\section{Takedown policy}

If you believe that this document breaches copyright please refer to the University of Manchester's Takedown Procedures [http://man.ac.uk/04Y6Bo] or contact uml.scholarlycommunications@manchester.ac.uk providing relevant details, so we can investigate your claim.

\section{OPEN ACCESS}




\title{
Manuscript Details
}

\section{Manuscript number}

Title
UFUG_2017_422_R4

Barriers and opportunities of combining social and ecological functions of urban green spaces - users' and landscape professionals' perspectives

\section{Article type}

Research Paper

\begin{abstract}
Combined provision of social and ecological functions of urban green spaces (UGSs) can facilitate sustainable development by combating the adverse effects of rapid urban growth. However, barriers and opportunities of such provision need to be better understood so that policy-makers and managers can ensure their benefits are realised. This paper addresses this by investigating user and manager preferences for different types, characteristics, facilities and activities associated with UGSs, and by exploring academic and managerial perceptions about policy and management practices. Empirical evidence from two UK cities - Manchester and Leeds - revealed that the barriers and opportunities to combining social and ecological functions in UGSs were linked to user demand; knowledge and understanding about UGS functions; and budget/funding. The research also indicated that addressing these issues would require the active promotion of a number of key priority areas. These included enhancing awareness and knowledge amongst both users and managers, the development of management guidelines linked to combining functions, and better use of context specific measures grounded in innovative techniques.
\end{abstract}

Keywords

Corresponding Author

Corresponding Author's Institution

Order of Authors

Suggested reviewers multifunctional greenspace; urban greenery; urban park; urban landscape ecology; sustainable urban development; urban planning

Ishtiaque Shams

University of Manchester

Ishtiaque Shams, Adam Barker

Konstantinos Tzoulas, Martin Dallimer, Nicola Dempsey

\section{Submission Files Included in this PDF}

\section{File Name [File Type]}

Response to Reviewers.docx [Response to Reviewers (without Author Details)]

Highlights.docx [Highlights]

Title page.docx [Title Page (with Author Details)]

Revised manucript.docx [Manuscript (without Author Details)]

Figures.docx [Figure]

Tables (final).docx [Table]

Appendix.docx [Data in Brief]

To view all the submission files, including those not included in the PDF, click on the manuscript title on your EVISE Homepage, then click 'Download zip file'.

\section{Research Data Related to this Submission}

There are no linked research data sets for this submission. The following reason is given:

Data will be made available on request 
- Combining UGS social and ecological functions is necessary for urban sustainability

- User perceptions were studied using questionnaire survey and photo elicitation

- Managers' and academics' preferences were studied using semi-structured interviews

- User and manager preferences were compatible with combining the functions

- User demand, user and manager knowledge, and funding act as barriers/opportunities 
Title: Barriers and opportunities of combining social and ecological functions of urban greenspaces users' and landscape professionals' perspectives

Keywords: multifunctional greenspace; urban greenery; urban park; urban landscape ecology; sustainable urban development; urban planning

Corresponding Author: Ishtiaque Shams, ishtiaque.shams@gmail.com

Corresponding Author's Institution: School of Environment Education and Development (SEED), The University of Manchester, UK 


\section{Introduction}

Urban areas are now home to more than half (54\% in 2015) of the world's population and that percentage is expected to rise rapidly (66\% in 2050) (United Nations, 2015). This rapid rate of urbanisation is likely to have significant social and environmental consequences in urban areas, particularly through land use and land cover changes which can hinder the delivery of ecological and social functions of natural landscapes (Elmqvist et al., 2013; Wolff et al., 2017). Adverse social impacts of urbanisation relate to the psychological and physical stress caused by reduced contact with nature, lack of places for social interaction or personal reflection, and air, water and noise pollution (Chen et al., 2013; Chen et al., 2018; Cox and Gaston, 2018). Similarly, urbanisation also leads to negative ecological consequences in the form of loss of habitat and ecosystems that support biodiversity (Secretariat of the Convention on Biological Diversity, 2012). These adverse impacts can potentially be mitigated by enhancing the provision of social and ecological functions within urban green spaces (UGSs) ${ }^{1}$ (Mukherjee and Takara, 2018; Threlfall and Kendal, 2018).

Social and ecological functions are interdependent and often included under the umbrella of ecosystem services (ES). Here, for analytical clarity, we describe ecological functions as the provision of structures (e.g. species composition, plant density) and processes (e.g. nutrient cycling) that in turn support regulating ES such as air purification, flood control and noise reduction (Niemelä et al., 2010; Rupprecht et al., 2015; Speak et al., 2015). Social function refers to the benefits that humans derive from these ES, including but not limited to recreational opportunities, aesthetic enjoyments, psychological well-being and physical health, enhancing social ties, and providing educational opportunities (Qin et al., 2013; Van den Berg et al., 2014). Mental health benefits are provided through observation (passive use) which entails viewing nature without being present in it (Parsons et al., 1998; Schutte and Malouff, 2018), and through exposure (active use) which entails experiencing nature by being in nature with a focus on exploration and adventure (Gidlow et al., 2016; Kaplan, 1995). Physical health benefits of UGSs result from reduced air pollution (Chen et al., 2018; Lovasi et al., 2008); enhanced opportunities for physical activities like cycling and outdoor exercising (Godbey, 2009; Keskinen et al., 2018) and the act of viewing and being in the presence of nature (Reddon and Durante, 2018; Ulrich, 1984).

While UGSs hold the potential to counteract the adverse impacts of urbanisation, they face pressure due to competition for land resources and funding (Haaland and van den Bosch, 2015). It is no longer feasible to provide a number of UGSs each with its own niche function. For instance, lack of land may force planners to choose between UGSs and commercial/housing developments, while demand for other recreation and amenity services like libraries and sports areas can cause funding constraints for UGSs (Hofmann et al., 2012; Hough, 2004). Furthermore, as cities become denser, UGSs might need to become smaller or more segregated which would impair their ability to provide habitats for biodiversity as well as making them less accessible (Botzat et al., 2016; Shwartz et al., 2014). Urban planning policy is increasingly recognising the need to make use of UGSs as a tool to counter the negative impacts of rapid urbanisation whilst ensuring the sustainability of their social and ecological functions (Schewenius et al., 2014).

\footnotetext{
${ }^{1}$ UGSs refer to all forms of urban vegetation including parks, gardens, lawns, forests, farmlands, brownfield sites, green roofs, etc. It is that subset of green space (refers to nature or natural areas) which is confined to the urban environment and that subset of open space (refers to open urban public spaces used for amenity and reaction) which are 'green' or vegetated.
} 
This has been supported by recent international development initiatives such as the 2030 Agenda for Sustainable Development and the United Nations Conference on Housing and Sustainable Urban Development (Habitat III) (United Nations, 2016, 2017), as well as large-scale multi-national research projects. Two of the most significant of these take the form of the Urban Biodiversity and Ecosystem Services (URBES) project and the European Commission funded GREEN SURGE project (Pauleit et al., 2017; Voigt et al., 2014).

Historically the aforementioned social and ecological functions of UGSs have been theorised, and consequently planned separately (Box and Harrison, 1993). This separation has resulted from differing, but parallel, responses to urban change. On the one hand, the threat of urban compaction and encroachment has led to a well-established conservation ethic rooted in the legal protection of important natural areas from development. On the other, the need to offset the negative consequences of urban living (increased pollution, stress, reduced physical mobility inter alia) has resulted in a preoccupation with the provision of recreational access opportunity (DTLR Urban Green Spaces Taskforce, 2002; Thompson, 2013). These differing urban agendas, however, often mask the reality of urban green space usage and functionality. Firstly, peoples' visitation of natural areas can also be considered a form of recreational activity and secondly, manicured parks and gardens often also support a wide range of biodiversity features (Box and Harrison, 1993). Most UGSs tend to provide both functions to some extent, despite not always being designed, planned and managed with both functions in mind (Connop et al., 2016; Haase et al., 2014a). However, to ensure long-term sustainability of functionality in the face of competing land uses and reduced public funding, these functions can be explicitly combined by making socially oriented UGSs (such as parks and gardens) more ecologically effective by naturalising certain areas within them, while ecological UGSs (such as nature reserves) can be made more socially beneficial by providing greater levels of access and establishing man-made facilities within them (Aronson et al., 2017). Doing so, will give rise to barriers/opportunities which will need to be studied and understood to better plan and manage existing and future UGSs.

Previous research into the barriers and opportunities associated with UGS provision has tended to assert three dominant areas of focus. Firstly, the role of socio-cultural differences has been found to influence green space usage and preferences and hence, can be a barrier/opportunity for combining social and ecological functions depending on what the users of specific sites/locales prefer (Haaland and van den Bosch, 2015; Lo and Jim, 2012; Lo and Jim, 2010). Various reasons have been suggested by researchers for this difference; including varied life-perceptions associated with different class groupings and varied degrees of assimilation by marginal social groups into dominant cultural norms (Hitchmough, 1994; Suckall et al., 2009; Urry, 1990). Secondly, users' knowledge about and previous experience with natural environments has been found to shape their preferences and perceptions (Kronenberg, 2015). Those with knowledge about the importance of natural areas and positive experiences in them are more inclined towards such environments than those who do not have such knowledge or experiences (Jim and Chen, 2006; Jim and Shan, 2013; Schroeder, 1987). Moreover, users' perceptions can also be influenced by what they expect from UGSs and can thus act as a hindrance/support for its implementation. Negative expectations from green spaces have been known to include safety and accessibility concerns, while positive expectations included mental restoration (Bjerke et al., 2006; Giles-Corti et al., 2005). Thirdly, the role of policy has been found to be a key institutional driver for combining social and ecological functions in situations where targets are clearly established and are accompanied by recommendations 
for planning, design, management and maintenance of green spaces (Kronenberg, 2015; Thierfelder and Kabisch, 2016). Research on UGSs has found that a lack of supportive policy provision can be a barrier to implementing quality green spaces and could therefore, also be a barrier for combining social and ecological functions as well (Haaland and van den Bosch, 2015; Haase et al., 2014b; O'Neil and Gallagher, 2014).

Due to the relationship between these issues and preferences and perceptions (Aronson et al., 2017; Threlfall and Kendal, 2018), understanding the views and attitudes of key actors is thus key to understanding barriers/opportunities. It is also necessary to understand how opportunities can be harnessed and barriers overcome through policy, planning and management. The perceptions of academics and managers who are involved in the formulation of policy guidelines through consultations and/or have first-hand experiences in management (collectively referred to as 'landscape professionals' in this study) can help elucidate this matter. Due to the potential policy implications of perceptions and preferences for UGS, stakeholder responses to UGS typologies and features have received attention in contemporary research debates (Botzat et al., 2016; Peschardt et al., 2012). Existing research has identified urban parks as the most preferred green space type (Wendel et al., 2012; Zhang et al., 2013). This is in line with Kaplan and Kaplan (1989) who stated that people have the highest preference for intermediate green spaces - something between open fields and dense forests. Specific attributes associated with this relate to the importance of safety, cleanliness, size, proximity and accessibility (Giles-Corti et al., 2005; Wendel et al., 2012; Zhang et al., 2013). These explanatory factors are discussed in turn. Safety is primarily related to people's perception of the density of vegetation. Woodlands which have a comparatively open canopy with no understory, for example, are considered safer than those having closed canopy with dense understory (Coles and Bussey, 2000; Jorgensen et al., 2002; Mathey et al., 2016). Interestingly however, some recent studies have indicated that both wild spaces and wild elements within green spaces have gained in popularity. (Harris et al., 2017; Southon et al., 2017) Cleanliness or maintenance of UGSs is often linked to higher visitor numbers, sense of security, and attractiveness (Boone et al., 2009; Crompton, 2001). Size of the green space was found to be important for people because of the diversity of amenities they provided. Larger green spaces can contain more of the desirable attributes, namely, trees, water features and bird life (Giles-Corti et al., 2005; Wendel et al., 2012). Schipperijn et al. (2010) and Peschardt et al. (2012) found that people preferred larger green spaces over nearby smaller ones if the larger ones were within a reasonable distance and there were no personal factors that reduced their mobility. The importance of accessibility as a determinant of green space visit frequency was highlighted by a number of studies (Conedera et al., 2015; Jim and Chen, 2006; Zhang et al., 2013). De Vries et al. (2003) and Giles-Corti et al. (2005) linked accessibility to the quality of the path system, while Crow et al. (2006) found dense vegetation to be inducing a sense of inaccessibility.

Among the preferred activities, walking was found to be overwhelmingly popular (Brown et al., 2014; Rupprecht et al., 2015; Schetke et al., 2016). Relaxing in or enjoying nature was also favoured by users of green spaces (Adinolfi et al., 2014; Rupprecht et al., 2015). Users primarily perceived UGSs as a means of achieving personal health and wellbeing and facilitating contact with nature (Jim and Shan, 2013; Lo and Jim, 2012; Madureira et al., 2015). Most studies on perception of biodiversity/naturalness of UGSs focused on varying naturalness of ecosystems or communities and concluded that moderate vegetation density is preferred by users over settings that were very open or very dense (Bjerke et al., 2006; Hofmann et al., 2012). Higher densities were generally less preferred due to 
perceptions of untidiness and lack of safety (Gatersleben and Andrews, 2013; Martens et al., 2011). Perceptions about biodiversity/naturalness were also influenced by overt and apparent management regimes and studies found that managed/designed landscapes were preferred over wild/naturalistic ones (Hofmann et al., 2012; Özgüner and Kendle, 2006). The reason for this can be explained by the prospect refuge theory which suggests that more accessible environments with clear fields of vision (prospect) and few hiding places (refuge) are more restorative than environments with low prospect and high refuge (Appleton, 1996). Other studies on perceptions about biodiversity focused on the species community scale and generally showed a positive perception about the diversity of species (Dallimer et al., 2012; Fuller et al., 2007). The amount of research on manager and practitioner preferences is low, with only Özgüner et al. (2007), Hofmann et al. (2012) and Hoyle et al. (2017) specifically studying landscape professionals' preference for naturalistic versus formal UGSs, and all reporting a positive perception and preference for naturalistic provision.

From the above discussion it can be stated that the role of barriers/opportunities to UGS implementation has been the focus of previous research inquiry and that these are driven by user and landscape professionals' preferences and perceptions. What is relatively unknown however, is the extent to which user and landscape professionals' preferences and perceptions have changed in the face of increasing urban pressures and policy goals and whether the same barriers/opportunities exist when UGSs are explicitly planned and designed for combining social and ecological functions (Choudhry et al., 2015; Hegetschweiler et al., 2017). On this basis, this paper considers the current status of user and landscape professionals' preferences and perceptions about UGSs and whether combining social and ecological functions can be considered a realistic management proposition. In doing so, particular attention is given to the identification and analysis of barriers/opportunities to combined management futures. In order to achieve these aims, the paper seeks to explore two main research questions: (1) what are users' and managers' preferences and perceptions about combining social and ecological functions of UGSs? and (2) what are academics' and managers' perceptions about UGS policy and management practices related to combining social and ecological functions? This paper thus provides a knowledge base which can help policy-makers formulate policy guidelines specific to planning and management of UGSs which combine the functions.

\section{Methods}

\section{Site selection}

Four green spaces in the UK were selected for this study - Roundhay Park and Middleton Park in the city of Leeds, and Heaton Park and Platt Fields Park in the city of Manchester (Appendix A). Selection was based on three key criteria: first, location within a distance of $5 \mathrm{~km}$ of the city centre; second, most deprived $10 \%$ Lower Layer Super Output Areas (LSOA) contained within site catchment areas; and third, size greater than $2 \mathrm{~km}^{2}$ (Figs. 1 and 2). Location within/near deprived core urban areas ensured greater variety in culture, knowledge and expectations among users. Size was considered because larger green spaces can offer larger, varied habitats and more facilities and characteristics for greater usage. Selection of green spaces with different features and characteristics helped to capture the perceptions and behaviour of a variety of users - two sites (Roundhay Park and Heaton Park) provided both functions while of the 
other two - Middleton Park, which is a Local Nature Reserve, served a more ecological function than social function, and Platt Fields Park, which is a smaller city-centre park, focused more on the social function. Following site selection there was an exploratory period in April 2015 when the selected sites were each visited twice - once on a weekday and once on a weekend between $11 \mathrm{am}$ and $5 \mathrm{pm}$ to judge their suitability for the study and also to note number of visitors. A pilot study, involving ten user interviews at Roundhay Park and one key informant interview, was conducted during this time, and subsequently, the interview questionnaires were amended to their current form to better meet the data collection requirements.

\section{User interviews}

The semi-structured intercept interviews comprised of closed and open-ended questions with a photo elicitation segment (Table 1). Intercept interviews involve selecting respondents by intercepting them at public places, park visitors in this case, and conducting an interview (Lavrakas, 2008). Photo elicitation is a method of interviewing which involves showing participants photographs during the interview process and asking for responses to the images. This enables the collection of additional data to that obtained via verbal interview (Harper, 2002). A total of 150 interviews were conducted between the months of May and July in 2015 and 2016 with park users visiting on weekdays or weekends between 11am and 5pm (Table 2). More interviews were conducted on weekends (120) than on weekdays (30) to reflect the ratio of weekend to weekday visitor numbers. No weekday interviews were conducted in Platt Fields park as too few users were recorded during the exploratory period. The selection process involved entering a section of the green space and approaching a potential interviewee on a random basis. Regardless of whether the interview target agreed to participate or not, a different section of the green space was entered for the next potential interview. Those interviewees who agreed to participate were given a brief overview of the study and asked for verbal consent, which they were allowed to withdraw and stop the interview at any time.

The first segment of the questionnaire included socio-economic profiling questions relating to the interviewee's age, gender, ethnicity and education level. The second segment contained Likert scale questions centred on preferences for UGS types, characteristics, facilities, and activities along with open-ended questions to establish the reasons behind the responses given. The third segment of the questionnaire contained the photo elicitation exercise which again, contained Likert scale questions to establish preference for nine UGS types based upon photographs depicting varying levels of naturalness and density (Appendix B). This segment also contained open-ended questions about the rationale behind the preferences and associated perceptions about the photographs. The approach recognised that naturalness and density can influence both the preferences and perceptions about green spaces as well as the level of ecological functionality the green spaces provide (Green Surge, 2017). Striking the right balance between the two was therefore essential in accounting for both social and ecological functions of green spaces and the photo elicitation exercise helped assess user acceptance of variations in this in a way that a normal interview could not. A subjective assessment of naturalness and density was used to select the photographs for this exercise - naturalness was assessed by the amount of explicitly visible human influence in the photographs in the form of formal gardens, ordered plantings, paved surfaces, paths, benches, water features and shelters; with natural photographs having none, mixed photographs having some, and formal photographs having the most. Density of vegetation in the photographs was 
assessed mainly by tree density and excluded ground flora density in natural and mixed photographs, and by density of the plant arrangements in formal photographs due to absence of trees.

While intercept interviews containing closed and open-ended questions are commonly used in UGS studies in conjunction with other methods like user observation studies, biodiversity surveys and mapping of UGS features (e.g. Carrus et al., 2015; Muratet et al., 2015; Voigt and Wurster, 2015; Wendel et al., 2012); photo-elicitation is not usually included. Previous studies using photographs to understand user preferences and perceptions have either involved off-site photo elicitation surveys (e.g. Bjerke et al., 2006) or on-site Visitor Employed Photography (VEP) (e.g. Nielsen et al., 2012; Qiu et al., 2013). Thus, the on-site photo elicitation employed by this study created a unique data collection opportunity - the respondents were present at an UGS during the interview and were subject to multi-sensory stimuli, such as, sound of birds, leaves, waterbodies, smell of flowers and view of greenery, which helped to elicit more detailed and varied responses (Adams and Guy, 2007). The mixed methods nature of these interviews required more time compared to standard questionnaire surveys, thus, limiting the total sample size. However, the methodology provided more qualitative depth than previous large scale off-site photo elicitation research (e.g., Bjerke et al., 2006) and postal/online quantitative surveys (e.g., Lo and Jim, 2012) which generated quantitative data for statistical analysis at the cost of qualitative depth.

\section{Key informant interviews}

Semi-structured interviews were conducted between May 2015 and May 2016 with landscape professionals involved in UGS research and management in the study areas (Appendix $C$ ). The interviews targeted regional, city and site level UGS managers as well as academics. While the managers could provide first-hand account of how compatible combining the functions was with their preferences, academics were included to provide an in-depth understanding of the barrier/opportunities and how they can be harnessed/overcome through policy and planning. Key informant interviews have been used in previous studies geared to understanding the perceptions of landscape professionals (e.g. Hofmann et al., 2012; Hoyle et al., 2017; Özgüner et al., 2007). These interviews typically contained elements of open ended in-depth ethnographic interviews (unstructured) as well as precise codable data gathering interviews (structured) (Fontana and Frey, 1994). In this research, the method was used to obtain standardised data on the 'what' questions (for example, what barriers and/or opportunities exist) and to obtain in-depth understandings on the 'why' and 'how' questions (for example, why the barriers exist and how they can be overcome).

A total of 12 interviews were conducted which included academic experts, and regional, local government and voluntary organisation managers (Table 3). The key informants were identified by reviewing the organograms of the organisations relevant for this study, namely, regional landscape/green space organisations, local government parks departments, NGOs involved in green space management, voluntary groups and universities. All respondents, including academics, were involved in consultation work which guided regional and local policy and planning of UGSs. Their points of views were considered important because they have been involved in either managing or researching existing UGSs and thus have great knowledge about what works and what does not, and the issues that arise due to dual provision, be it problems or benefits. Whilst the opinions of other landscape professionals operating with the 
case study location would have been of contextual interest, they were not included in this particular study due to the need to focus on case-study based actors.

Participants were recruited via email/telephone, provided information sheets about the research and their role, asked to choose between face-to-face, e-mail and telephone interview, and to suggest potential interview date, time and location. All participants chose face-to-face interviews which were conducted in their work places during normal working hours. They were given at least two weeks to respond before follow-up reminder e-mails or telephone calls were made. Out of the 28 contacted, twelve participated in the study while the remaining sixteen either did not respond to follow-ups or declined to sit for the interview due to time constraints.

The interviews were approximately 60-minutes long and mainly covered three themes with questions slightly changed for informants at different levels, namely, regional, city and site. The themes were: (1) key actors and policies, which covered questions on key policies and actors responsible for managing the green spaces in the region/city; (2) state of the green spaces, which covered questions about the current condition of the social and ecological functions in UGSs and the factors which led to the UGSs being in their current state; and (3) multifunctionality, which covered questions about providing both social and ecological functions within the same UGSs, the conflicts that may arise and measures to alleviate them.

\section{Data analysis}

The preferences for UGS types, characteristics, facilities, and activities, and photographs from the user interviews were entered in IBM SPSS 23 to study the spread and variance of the data. Respondents' comments about the photographs, in general and about the reasons behind the ratings, were transcribed and grouped into themes. The themes were different for each photograph but broadly covered descriptors (e.g., dark, formal, colourful); elements within the photographs (e.g., flowers, trees, water feature); activities the green spaces in the photographs can facilitate (e.g., exploration, relaxing, walking); and general comments about personal preferences and perceptions. The comments within the themes were analysed for each photograph to synthesise the key findings.

Qualitative data from the key informant interviews were transcribed and sorted into two themes, as per the research questions, which were analysed to synthesise key intra-theme discourses. The themes were: preferences for urban green space types, characteristics and facilities; and barriers and/or opportunities of combining social and ecological functions.

\section{Results}

\section{User preference for UGSs types, characteristics, facilities and activities}

Urban parks were the most visited UGS (Table 4) as they provide all the preferred characteristic and activities (see below). Moreover, they provide a mixture of natural and manicured elements which were also viewed preferably by users (see following section).

The highest rated characteristics were cleanliness, variation in the natural landscape, safety, accessibility and size (Table 4). Per the respondents, cleanliness encompasses closely mown grass, lack of litter, and sense of maintenance 
and management. Variation in the natural landscape was considered important by respondents due to the opportunity for multiple activity types - waterbodies were considered good for walking around, sitting beside, boating, fishing and for dogs to play in, while woodlands and parklands were considered ideal for going for a walk and for children to play in, enjoy the weather or have a picnic, respectively. Safety of the UGSs was linked to deprivation and crime rates of surrounding neighbourhoods, density of understory vegetation and lack of clear walking paths. Accessibility was associated with evenness of the landscape and the availability of wide pathways. Regarding size, respondents stated that larger UGSs shielded them from the sights and noises of the city and allowed them to connect with nature, provided greater opportunities for a variety of activities like playing, running and dog walking, and provided enough space for users on busy days.

Toilets, walking or cycling paths, availability of parking areas, and benches for sitting were the most preferred facilities (Table 4). Toilets, despite their high importance, were not considered a limiting factor in terms of UGS usability, but rather an enhancing factor for user experience. Walking or cycling paths were linked to the accessibility and safety issues raised above. They were important factors for people with prams or mobility scooters, and for those who did not want to go off-track due to perceptions of risk and danger. Regarding benches, one respondent commented that their availability gives UGSs a communal feel.

Getting fresh air/relaxing in nature, walking, playing with children/enjoying family time, general socialising and picnics/barbecue were ranked as the most important activities (Table 4). These can be broadly grouped into sedentary (requiring low physical effort), mobile (requiring moderate physical effort) or vigorous (requiring high physical effort) activities, and individual (can be done by an individual alone) or group (cannot be done by an individual alone) activities. The increasing effort level of the first three categories reflect a shift from mental to physical wellbeing, with the assumption that more vigorous activities are undertaken with physical health in mind. The last two categories reflect the usage of UGSs either as personal space or as a social space. Using this categorisation for the preferred activities, it can be stated that UGSs serve both as social and personal space and are used mainly for mental wellbeing.

\section{User perceptions about naturalness and density}

Respondents preferred 'natural' UGS photographs because they imparted a sense of connecting with nature or being in less urban, less manmade environments, and associated them to preferred outdoor activities like walking, cycling and camping (Table 4). The woodland photographs ('dense' and 'medium-dense' natural) were particularly preferred as they provided a sense of exploration and adventure. However, those who disliked the woodland photographs felt that they conveyed a sense of being derelict or not having enough natural or manmade features to hold their interest. The 'dense natural' photograph was additionally disliked due to a perception of darkness, as respondents felt the dense canopy would make the area dark, cool and unpleasant. Perceptions of discomfort in terms of unsuitability for relaxing activities like walking and sitting, was expressed as a reason for disliking both the 'dense' and 'sparse' natural photographs which had understory plants and overgrown grass at ground level. Respondents who were indifferent about the 'natural' photographs either liked the green spaces but were unable to visit them due to unavailability, or did not like the green spaces but appreciated their importance for other users and wildlife. 
The 'mixed' photographs were positively perceived because their naturalness was complemented with social elements like paths, benches, other people, and open spaces (Table 4). Presence of other people in the green space reflected safety and popularity. The paved paths, mown grass and lower tree density created a perception of comfort and accessibility. Respondents who disliked the photographs were primarily the ones who liked the natural photographs and thus found features like neat and sparse arrangement of trees and presence of other people in the photographs unappealing. The 'sparse mixed' photograph was especially disliked due to the presence of flowers in formal settings. Respondent who were indifferent about the 'mixed' photographs stated their preference for either more natural or more manicured areas. However, they still considered such green spaces useful due to their proximity to residences, their provision of children's play areas and their suitability for dog walking.

'Manicured' photographs were primarily disliked as respondents perceived them to be too manmade, formal and managed (Table 4). They were considered nice to pass by and look at but unsuitable for visiting and spending time in. The water features in 'medium-dense' and 'sparse' manicured photographs made them more attractive to respondents compared to the 'dense manicured' photograph, which was perceived as overgrown, untidy and unmanaged. Among the respondents who liked the 'manicured' photographs, the presence of flowers, colours, and water features, and the sense of being maintained were cited as reasons.

\section{Landscape professionals' preference for UGS types, characteristics and facilities}

When considering green space provision, landscape professionals indicated that they adopt a typological approach based on one or more of the following principles:

Need/demand based green spaces - according to all respondents, this meant prioritising user demand and need in specific areas or for the whole city based on data from needs assessments which can include one or more of the following: user surveys, public discussion forums, online platforms and analysis of demographic and current provision data.

Multifunctional smaller green spaces in urban core - this was considered a logical outcome of the city level needs assessments by respondents GOVERNMENT-A and GOVERNMENT-D, as it would account for the land shortage and wide range of needs arising from the greater socio-economic and demographic diversity in the core urban areas.

"[Smaller UGSs in urban core] need to accommodate a range of features and facilities. Typically, they will include areas of informal or formal recreation, play facilities, formal landscaping, a path network, trees, natural areas." (GOVERNMENT-A)

A shift from manicured/formal to mixed UGSs - three respondents stated that knowledge about ecosystem services had changed the mentality of managers and users alike. Managers employ relaxed mowing practices (leaving grass unmown for long periods each year) and plant woodlands to 'create' natural areas within UGSs. GOVERNMENT-B stated that policy-makers are starting to move away from the idea that UGSs should be closely mown, neat and tidy, with regularly pruned flower beds, and "maybe a 'keep off the grass' sign". VOLUNTARY-A, added that users want more than a horticultural showcase from their UGSs, they want "wilderness in the urban concrete jungle."

Landscape professionals' preference of UGS characteristics were based on: 
Proximity-size relationships - seven respondents mentioned a hierarchy of how much of green space was needed for how many and at what distance.

"The idea is to have smaller green spaces relatively closer to residences and then medium-sized ones further away and larger ones even further away, since people are theoretically willing to make a longer trip for them."

(ACADEMIC-B)

Balance between social and ecological functions - the characteristics all respondents highlighted included accessibility, aesthetics, biodiversity and variation in the natural landscapes, and they were interlinked in the sense that they need to be balanced to provide high quality UGSs.

Landscape professionals' preferences for facilities was based on one of two approaches:

Providing something for everyone - three respondents felt that UGSs should ideally provide children's play areas, multi-use games areas, paths for walking/running, benches for older people, and sports facilities like playing pitches and bowling greens, thus, catering for as many needs as possible.

Local need-based approach - seven respondents recognised that while something for everyone was ideal, it was not always possible in smaller, budget constrained neighbourhood green spaces. In those instances, the facilities that were most important for that specific green space at that particular location had to be prioritised.

\section{Opportunities and/or barriers of combining social and ecological functions}

Landscape professionals stated the following opportunities:

Creating inclusive spaces - all respondents stated that the most obvious opportunity is making UGSs more inclusive of different user types - if each neighbourhood had a green space which combined both functions, neither manicured nor natural UGS users would feel disenfranchised.

Making the urban matrix biodiversity-friendly - nine of the respondents mentioned this as an outcome of improving the naturalness/ecological function of smaller UGSs. These can act as stepping stones within the urban matrix and provide food for birds and insects. Formal areas like flower beds were seen as having a supportive biodiversity role.

Ensuring survival of important urban ecosystems - three of the respondents stated that improving the social function can protect important urban ecosystems from development pressure. They provided examples of UGSs in London, located in areas of high property prices, and having high ecological value due to their age and structure, which survived due to the number of visitors they receive annually.

Bringing people closer to nature - five respondents stated that making UGSs more natural can enhance peoples experience.

"If they are living in a flat where they have no garden space, or if they are in a terraced house with no backyard, where would they then experience wildlife first-hand? When we say wildlife, we are talking about invertebrates, birds, insects, small mammals. But they might not ever get that opportunity in a city environment to do that." (GOVERNMENT-B) 
(Lack of) funding - eight respondents stated that while lack of funding for building paths and play areas in smaller UGSs significantly undermined their social function, it partly facilitated their ecological function due to reduced mowing activity and increased grass size - inadvertently prompting a shift from manicured/formal to mixed UGSs. Lack of funding also, indirectly, meant a greater community involvement through voluntary groups (e.g., 'Friends of' groups) who filled the gap in resource management. This in turn, was noted to give the community a greater voice in management decisions. Respondents further mentioned how lack of funding made it difficult to provide social facilities (like outdoor play areas) along with innovative ecological features (such as reed beds).

Landscape professionals identified the following barriers:

Conflicts between users and managers - eight respondents felt that management activities such as tree removal, relaxed mowing and the planting of flower beds, could be met with both rebuke and praise from different users depending on their perceptions. Both users and managers, for example, sometimes perceived areas set aside for wildflowers as being unmanaged. There was also the view that whilst tree planting might be deemed a threat to open style vistas, tree removal, conversely, tended to be associated with a reduction of natural provision.

Conflicts between the functions themselves - four respondents stated that ecological function in the form of natural provisions can negatively influence the social function - e.g., some users stopped visiting an UGS after woodland plantations. Social function can sometimes negatively impact the ecological function, according to VOLUNTARY-A e.g., cyclists destroying wildflowers by straying off their trail.

Landscape professionals' suggestions for overcoming the barriers:

Educating and informing the public and managers - all respondents stated that managers and users need to be educated about the importance of biodiversity and naturalistic management practices, and that users also need to be informed about management plans beforehand. They suggested doing this through school campaigns, bird walks, tree trails, newsletters, interpretation boards, signage, website, social media, press releases, informing user volunteer groups, and providing examples of other successful cases.

Increasing public involvement in management - this was suggested by three respondents as a means to ensure users understand management decisions and take ownership of the park. This can be done by involving user volunteer groups and community representatives in decision-making and implementation stages.

Taking innovative management and planning measures - REGIONAL-A provided an example of how innovation can overcome negative public perception of natural areas - formal elements can be placed on outer regions of UGSs and informal features like woodlands and grasslands can be hidden within. Another method, mentioned by three of the respondents, was to add colour and variety to rank vegetation areas by introducing wildflowers. Site characteristics like marshy areas, dense undergrowth, and waterbodies can naturally make it difficult for users to reach ecologically sensitive sections. One way of creating a non-intrusive artificial barrier, as suggested by GOVERNMENT-D, is limiting the number of paths leading to or creating them in a way to steer people away from ecologically important areas. 


\section{Discussion}

This paper has provided an up-to-date baseline understanding of user and professional perceptions and preferences for UGS and explored the management implications of co-provision (Figure 3). The paper has found that combining social and ecological functions in UGSs is a viable option and that the interdependence of barriers and opportunities means that pathways can be identified to harness potential and promote compatibility. The research therefore, has secured fresh insights into the role of combined provision UGSs within a context of increasing urban pressure. Through the methodological approach adopted as part of the research, we have found that barriers/opportunities for comanagement can broadly be grouped under three themes - user demand; knowledge and understanding of UGS functions; and budget/funding.

In analysing user preferences and perceptions, the study found that user demand can act both as a barrier and opportunity. For example, some preferred activities or goals of UGS visitation like relaxing, playing with children, and enjoying barbecue/picnics with friends and family require open spaces with low or less significant biodiversity such as open lawns. Other desired activities need to be or can be achieved in much wilder areas where people can walk, escape, connect with nature, and have restorative experiences. This finding coincides with findings of similar studies like Carrus et al. (2015); Voigt et al. (2014); Voigt and Wurster (2015) and highlights the need for combining social and ecological functions to cater for user preferences. Additionally, this study found that natural areas are perceived favourably at high densities. This contradicts earlier studies in user perceptions like Bjerke et al. (2006) but supports more recent studies like Threlfall and Kendal (2018) and the assumption is that UGS users are becoming more accepting of wilder (less overtly maintained/managed) elements due to greater ecological knowledge and understanding. This preference was found to decrease with decreasing tree density and/or increasing ground flora density in this study. This aligns with the prospect refuge theory (Appleton, 1996; Gatersleben and Andrews, 2013) and the landscape characteristic of 'mystery' (Kaplan \& Kaplan, 1989). Respondents in this study revealed that they seek out environments with particular combinations of openness and enclosure - a balanced arrangement of prospect and refuge. This balance, when achieved, tends to entice exploratory behaviour among the respondents, in other words, it invokes a sense of 'mystery' - the degree to which landscapes draw people towards them by creating an intrigue about what lies ahead.

However, this study also found that UGSs that are perceived to lack natural aspects, irrespectively of prospect-refuge, are viewed unfavourably and are considered too manmade, formal and managed. Mixed UGSs are generally preferred by users at high and medium tree densities due to the presence of manmade features like paths, benches, and open spaces within the natural landscapes. This supports Voigt et al. (2014) who found that infrastructural facilities and amenities are as important as ecosystem functions and biotic elements for cultural ecosystem services. Taking all of above into consideration, it can be stated that policy-makers and UGS managers should note that natural UGSs offer opportunities for users to connect with oneself and one's natural environment, but many of them cannot escape the sense of insecurity they have about nature nor their habituation with neat, tidy and comfortable provisions in their urban environments. User preference has shifted towards more naturalistic provisions but not necessarily towards a desire for less management. In other words, UGSs should be a configuration that provides a natural setting without being completely alienated from the inherent characteristics of the surroundings that is 'urban.' 
User demand and knowledge are interlinked - knowledge about human wellbeing and biodiversity functions of UGSs positively influences demand for combining functions while lack of such knowledge leads to negativity; e.g., considering woodlands unsafe, wildflowers untidy and biodiversity harmful. The knowledge and understanding of the managers is also important - managers interviewed in this study who were positive about combining functions had knowledge about the importance of human contact with nature and making the urban matrix biodiversity-friendly. Previous studies like Hoyle et al. (2017) and Hofmann et al. (2012) showed that landscape professionals are not opposed to naturalistic and multifunctional UGS provisions. However, as revealed by this study, their inclination towards multifunctionality is not limited to and does not necessarily entail combining social and ecological functions - it can be a combination of different social functions. When combining social and ecological functions, the landscape professionals highlighted the importance of balancing the functions to ensure they do not spatially disenfranchise any user group. Thus, a policy apparatus which supports knowledge and information dissemination about benefits of combined provision to users and managers, as well as informing users about management practices, needs to be implemented.

The issue of funding proved to be a nuanced and complex area of concern. Lack of funding was found to have clearly impacted on an ability to provide advanced forms of provision and proactive management support. In particular, landscape professionals found that limited funds meant that it was difficult to combine costly social facilities with innovative ecological features (such as reed beds). It also impacted upon the ability to establish monitoring regimes based on social and ecological surveys. Nevertheless, ironically, lack of funding was also found to play an indirect role in supporting implementation since urban landscape professionals tend to consider naturalistic UGS provision and management less costly than their formal counterparts (Hoyle et al., 2017; Threlfall and Kendal, 2018). This study found that a lack of funding has forced managers to implement relaxed mowing in areas which were previously closely mown. This, according to Buri et al. (2013), can enhance their ecological functionality. Managers are also forced to choose which facilities to prioritise. This can lead to costly social facilities, such as sports areas, being replaced with more ecologically favourable and cost-effective grasslands or meadows. Since lack of funding can act as an opportunity, additional funds are often better employed in supporting information dissemination and education schemes and promoting innovative management practices which can overcome conflicts between social usage and ecological provision.

The methodology of this research differed from previous research in the field which primarily focused on the use of large-scale quantitative surveys (e.g. Lo \& Jim, 2012, Ozguner et al., 2007) and photo-elicitation exercises (e.g. Bjerke et al., 2006). Whilst useful, these have centred on statistical analysis rather than qualitative exploration. The use of a more qualitative approach based on intercept engagement and in-depth key-informant interviews has enabled a deeper picture of preferences and perceptions to be established. Nevertheless, we acknowledge a number of limitations to the methods applied. The use of qualitative user interviews required more time to complete than a more quantitative approach. This, in-turn, reduced the total sample size available and limited opportunity for correlationbased analyses, (such as the relationship between demographic data/study sites and user preferences and perceptions). Furthermore, we acknowledge that the total number of key-informant interviews was lower than planned due to the limited availability of local government authorities and park managers. 


\section{Acknowledgement}

This paper is part of a Doctoral Dissertation funded by the President's Doctoral Scholar Award, University of Manchester, UK.

\section{Reference}

Adams, M., Guy, S., 2007. Editorial: Senses and the city. The Senses and Society 2, 133-136.

Adinolfi, C., Suárez-Cáceres, G.P., Cariñanos, P., 2014. Relation between visitors' behaviour and characteristics of green spaces in the city of Granada, south-eastern Spain. Urban Forestry \& Urban Greening 13, 534-542.

Appleton, J., 1996. The experience of landscape. Wiley Chichester.

Aronson, M.F.J., Lepczyk, C.A., Evans, K.L., Goddard, M.A., Lerman, S.B., Maclvor, J.S., Nilon, C.H., Vargo, T., 2017. Biodiversity in the city: key challenges for urban green space management. Frontiers in Ecology and the Environment 15, 189-196.

Bjerke, T., Østdahl, T., Thrane, C., Strumse, E., 2006. Vegetation density of urban parks and perceived appropriateness for recreation. Urban Forestry \& Urban Greening 5, 35-44.

Boone, C.G., Buckley, G.L., Grove, J.M., Sister, C., 2009. Parks and people: An environmental justice inquiry in Baltimore, Maryland. Annals of the Association of American Geographers 99, 767-787.

Botzat, A., Fischer, L.K., Kowarik, I., 2016. Unexploited opportunities in understanding liveable and biodiverse cities. A review on urban biodiversity perception and valuation. Global Environmental Change 39, 220-233.

Box, J., Harrison, C., 1993. Natural Spaces in Urban Places. TCPA 62, 231-235.

Brown, G., Schebella, M.F., Weber, D., 2014. Using participatory GIS to measure physical activity and urban park benefits. Landscape and Urban Planning 121, 34-44. 
Buri, P., Arlettaz, R., Humbert, J.-Y., 2013. Delaying mowing and leaving uncut refuges boosts orthopterans in extensively managed meadows: Evidence drawn from field-scale experimentation. Agriculture, Ecosystems \& Environment 181, 22-30.

Carrus, G., Scopelliti, M., Lafortezza, R., Colangelo, G., Ferrini, F., Salbitano, F., Agrimi, M., Portoghesi, L., Semenzato, P., Sanesi, G., 2015. Go greener, feel better? The positive effects of biodiversity on the well-being of individuals visiting urban and peri-urban green areas. Landscape and Urban Planning 134, 221-228.

Chen, L., Sun, R., Liu, H., 2013. Eco-environmental effects of urban landscape pattern changes: Progresses, problems, and perspectives. Shengtai Xuebao/ Acta Ecologica Sinica 33, 1042-1050.

Chen, T., Lang, W., Chan, E., Philipp, C.H., 2018. Lhasa: Urbanising China in the frontier regions. Cities 74, 343-353.

Choudhry, K.Z., Coles, R., Qureshi, S., Ashford, R., Khan, S., Mir, R.R., 2015. A review of methodologies used in studies investigating human behaviour as determinant of outcome for exposure to 'naturalistic and urban environments'. Urban Forestry \& Urban Greening 14, 527-537.

Coles, R., Bussey, S., 2000. Urban forest landscapes in the UK-progressing the social agenda. Landscape and Urban Planning 52, 181-188.

Conedera, M., Del Biaggio, A., Seeland, K., Moretti, M., Home, R., 2015. Residents' preferences and use of urban and peri-urban green spaces in a Swiss mountainous region of the Southern Alps. Urban Forestry \& Urban Greening 14, 139-147.

Connop, S., Vandergert, P., Eisenberg, B., Collier, M.J., Nash, C., Clough, J., Newport, D., 2016. Renaturing cities using a regionally-focused biodiversity-led multifunctional benefits approach to urban green infrastructure. Environmental Science \& Policy 62, 99-111.

Cox, D.T., Gaston, K.J., 2018. Human-nature interactions and the consequences and drivers of provisioning wildlife. Phil. Trans. R. Soc. B 373, 20170092.

Crompton, J.L., 2001. The impact of parks on property values: A review of the empirical evidence. Journal of Leisure Research 33, 1-31.

Crow, T., Brown, T., De Young, R., 2006. The Riverside and Berwyn experience: Contrasts in landscape structure, perceptions of the urban landscape, and their effects on people. Landscape and Urban Planning 75, 282-299.

Dallimer, M., Irvine, K.N., Skinner, A.M., Davies, Z.G., Rouquette, J.R., Maltby, L.L., Warren, P.H., Armsworth, P.R., Gaston, K.J., 2012. Biodiversity and the feel-good factor: understanding associations between self-reported human well-being and species richness. BioScience 62, 47-55.

De Vries, S., Verheij, R.A., Groenewegen, P.P., Spreeuwenberg, P., 2003. Natural environments - healthy environments? An exploratory analysis of the relationship between greenspace and health. Environment and Planning 35, 1717-1731.

DTLR Urban Green Spaces Taskforce, 2002. Green spaces, better places: final report of the Urban Green Spaces Taskforce. Department for Transport, Local Government and the Regions (DTLR).

Elmqvist, T., Fragkias, M., Goodness, J., Güneralp, B., Marcotullio, P.J., McDonald, R.I., Parnell, S., Schewenius, M., Sendstad, M., Seto, K.C., Wilkinson, C., 2013. Urbanization, biodiversity and ecosystem services: challenges and opportunities: a global assessment. Springer London.

Fontana, A., Frey, J., 1994. Interviewing: The art of science, in: Denzin, N.K., Lincoln, Y.S. (Eds.), Handbook of Qualitative Research. Sage Publications, Thousand Oaks, pp. 361-376.

Fuller, R.A., Irvine, K.N., Devine-Wright, P., Warren, P.H., Gaston, K.J., 2007. Psychological benefits of greenspace increase with biodiversity. Biology Letters 3, 390-394.

Gatersleben, B., Andrews, M., 2013. When walking in nature is not restorative-The role of prospect and refuge. Health \& Place 20, 91-101.

Gidlow, C.J., Jones, M.V., Hurst, G., Masterson, D., Clark-Carter, D., Tarvainen, M.P., Smith, G., Nieuwenhuijsen, M., 2016. Where to put your best foot forward: Psycho-physiological responses to walking in natural and urban environments. Journal of Environmental Psychology 45, 22-29. 
Giles-Corti, B., Broomhall, M.H., Knuiman, M., Collins, C., Douglas, K., Ng, K., Lange, A., Donovan, R.J., 2005.

Increasing walking: how important is distance to, attractiveness, and size of public open space? American Journal of Preventive Medicine 28, 169-176.

Godbey, G., 2009. Outdoor Recreation, Health, and Wellness - Understanding and Enhancing the Relationship. Resources for the Future, Washington DC.

Green Surge, 2017. The Green Surge Handbook.

Haaland, C., van den Bosch, C.K., 2015. Challenges and strategies for urban green-space planning in cities undergoing densification: A review. Urban Forestry \& Urban Greening 14, 760-771.

Haase, D., Frantzeskaki, N., Elmqvist, T., 2014a. Ecosystem Services in Urban Landscapes: Practical Applications and Governance Implications. AMBIO 43, 407-412.

Haase, D., Larondelle, N., Andersson, E., Artmann, M., Borgström, S., Breuste, J., Gomez-Baggethun, E., Gren, Å., Hamstead, Z., Hansen, R., 2014b. A quantitative review of urban ecosystem service assessments: concepts, models, and implementation. Ambio 43, 413-433.

Harper, D., 2002. Talking about pictures: a case for photo elicitation. Visual Studies 17, 13-26.

Harris, V., Kendal, D., Hahs, A.K., Threlfall, C.G., 2017. Green space context and vegetation complexity shape people's preferences for urban public parks and residential gardens. Landscape Research, 1-13.

Hegetschweiler, K.T., de Vries, S., Arnberger, A., Bell, S., Brennan, M., Siter, N., Olafsson, A.S., Voigt, A., Hunziker, M., 2017. Linking demand and supply factors in identifying cultural ecosystem services of urban green infrastructures: $A$ review of European studies. Urban Forestry \& Urban Greening 21, 48-59.

Hitchmough, J.D., 1994. Urban Landscape Management. Inkata Press Pty, Sydney.

Hofmann, M., Westermann, J.R., Kowarik, I., van der Meer, E., 2012. Perceptions of parks and urban derelict land by landscape planners and residents. Urban Forestry \& Urban Greening 11, 303-312.

Hough, M., 2004. Cities and Natural Process: A basis for sustainability, 2 ed. Routledge, London.

Hoyle, H., Jorgensen, A., Warren, P., Dunnett, N., Evans, K., 2017. "Not in their front yard" The opportunities and challenges of introducing perennial urban meadows: A local authority stakeholder perspective. Urban Forestry \& Urban Greening 25, 139-149.

Jim, C., Chen, W.Y., 2006. Perception and attitude of residents toward urban green spaces in Guangzhou (China). Environmental Management 38, 338-349.

Jim, C., Shan, X., 2013. Socioeconomic effect on perception of urban green spaces in Guangzhou, China. Cities 31, 123-131.

Jorgensen, A., Hitchmough, J., Calvert, T., 2002. Woodland spaces and edges: their impact on perception of safety and preference. Landscape and urban planning 60, 135-150.

Kaplan, R., Kaplan, S., 1989. The Experience of Nature: A Psychological Perspective. Cambridge University Press, Cambridge.

Kaplan, S., 1995. The restorative benefits of nature: towards an integrative framework. Journal of Environmental Psychology 15, 169-182.

Keskinen, K.E., Rantakokko, M., Suomi, K., Rantanen, T., Portegijs, E., 2018. Nature as a facilitator for physical activity: Defining relationships between the objective and perceived environment and physical activity among community-dwelling older people. Health \& Place 49, 111-119.

Kronenberg, J., 2015. Why not to green a city? Institutional barriers to preserving urban ecosystem services. Ecosystem Services 12, 218-227.

Lavrakas, P.J., 2008. Encyclopedia of Survey Research Methods. Sage Publications, London.

Lo, A.Y., Jim, C., 2012. Citizen attitude and expectation towards greenspace provision in compact urban milieu. Land Use Policy 29, 577-586.

Lo, A.Y.H., Jim, C.Y., 2010. Differential community effects on perception and use of urban greenspaces. Cities 27 , 430-442. 
Lovasi, G.S., Quinn, J.W., Neckerman, K.M., Perzanowski, M.S., Rundle, A., 2008. Children living in areas with more street trees have lower asthma prevalence. Journal of Epidemiology and Community Health 62, 647-649.

Madureira, H., Nunes, F., Oliveira, J.V., Cormier, L., Madureira, T., 2015. Urban residents' beliefs concerning green space benefits in four cities in France and Portugal. Urban Forestry \& Urban Greening 14, 56-64.

Martens, D., Gutscher, H., Bauer, N., 2011. Walking in "wild" and "tended" urban forests: The impact on psychological well-being. Journal of Environmental Psychology 31, 36-44.

Mathey, J., Arndt, T., Banse, J., Rink, D., 2016. Public perception of spontaneous vegetation on brownfields in urban areas-Results from surveys in Dresden and Leipzig (Germany). Urban Forestry \& Urban Greening.

Mukherjee, M., Takara, K., 2018. Urban green space as a countermeasure to increasing urban risk and the UGS-3CC resilience framework. International Journal of Disaster Risk Reduction.

Muratet, A., Pellegrini, P., Dufour, A.-B., Arrif, T., Chiron, F., 2015. Perception and knowledge of plant diversity among urban park users. Landscape and Urban Planning 137, 95-106.

Nielsen, A.B., Heyman, E., Richnau, G., 2012. Liked, disliked and unseen forest attributes: Relation to modes of viewing and cognitive constructs. Journal of Environmental Management 113, 456-466.

Niemelä, J., Saarela, S.-R., Söderman, T., Kopperoinen, L., Yli-Pelkonen, V., Väre, S., Kotze, D.J., 2010. Using the ecosystem services approach for better planning and conservation of urban green spaces: a Finland case study. Biodiversity and Conservation 19, 3225-3243.

O'Neil, J.A., Gallagher, C.E., 2014. Determining What is Important in Terms of the Quality of an Urban Green Network: A Study of Urban Planning in England and Scotland. Planning Practice and Research 29, 202-216.

Özgüner, H., Kendle, A., Bisgrove, R., 2007. Attitudes of landscape professionals towards naturalistic versus formal urban landscapes in the UK. Landscape and Urban Planning 81, 34-45.

Özgüner, H., Kendle, A.D., 2006. Public attitudes towards naturalistic versus designed landscapes in the city of Sheffield (UK). Landscape and Urban Planning 74, 139-157.

Parsons, R., Tassinary, L.G., Ulrich, R.S., Hebl, M.R., Grossman-Alexander, M., 1998. The view from the road: implications for stress recovery and immunization. Journal of Environmental Psychology 18, 113-140.

Pauleit, S., Hansen, R., Rall, E.L., Zölch, T., Andersson, E., Luz, A.C., Szaraz, L., Tosics, I., Vierikko, K., 2017. Urban Landscapes and Green Infrastructure. Oxford Research Encyclopedia of Environmental Science.

Peschardt, K.K., Schipperijn, J., Stigsdotter, U.K., 2012. Use of Small Public Urban Green Spaces (SPUGS). Urban Forestry \& Urban Greening 11, 235-244.

Qin, J., Zhou, X., Sun, C., Leng, H., Lian, Z., 2013. Influence of green spaces on environmental satisfaction and physiological status of urban residents. Urban Forestry \& Urban Greening 12, 490-497.

Qiu, L., Lindberg, S., Nielsen, A.B., 2013. Is biodiversity attractive?-On-site perception of recreational and biodiversity values in urban green space. Landscape and Urban Planning 119, 136-146.

Reddon, J.R., Durante, S.B., 2018. Nature exposure sufficiency and insufficiency: The benefits of environmental preservation. Medical Hypotheses 110, 38-41.

Rupprecht, C.D., Byrne, J.A., Ueda, H., Lo, A.Y., 2015. 'It's real, not fake like a park': Residents' perception and use of informal urban green-space in Brisbane, Australia and Sapporo, Japan. Landscape and Urban Planning 143, $205-218$.

Schetke, S., Qureshi, S., Lautenbach, S., Kabisch, N., 2016. What determines the use of urban green spaces in highly urbanized areas? - Examples from two fast growing Asian cities. Urban Forestry \& Urban Greening 16, 150-159.

Schewenius, M., McPhearson, T., Elmqvist, T., 2014. Opportunities for Increasing Resilience and Sustainability of Urban Social-Ecological Systems: Insights from the URBES and the Cities and Biodiversity Outlook Projects. AMBIO 43, 434-444.

Schipperijn, J., Stigsdotter, U.K., Randrup, T.B., Troelsen, J., 2010. Influences on the use of urban green space-A case study in Odense, Denmark. Urban Forestry \& Urban Greening 9, 25-32.

Schroeder, H.W., 1987. Dimensions of variation in urban park preference: a psychophysical analysis. Journal of Environmental Psychology 7, 123-141. 
Schutte, N.S., Malouff, J.M., 2018. Mindfulness and connectedness to nature: A meta-analytic investigation. Personality and Individual Differences 127, 10-14.

Secretariat of the Convention on Biological Diversity, 2012. Cities and Biodiversity Outlook. Convention on Biological Diversity, Hyderabad.

Shwartz, A., Turbé, A., Julliard, R., Simon, L., Prévot, A.-C., 2014. Outstanding challenges for urban conservation research and action. Global Environmental Change 28, 39-49.

Southon, G.E., Jorgensen, A., Dunnett, N., Hoyle, H., Evans, K.L., 2017. Biodiverse perennial meadows have aesthetic value and increase residents' perceptions of site quality in urban green-space. Landscape and Urban Planning 158, 105-118.

Speak, A.F., Mizgajski, A., Borysiak, J., 2015. Allotment gardens and parks: Provision of ecosystem services with an emphasis on biodiversity. Urban Forestry \& Urban Greening 14, 772-781.

Suckall, N., Fraser, E.D., Cooper, T., Quinn, C., 2009. Visitor perceptions of rural landscapes: A case study in the Peak District National Park, England. Journal of Environmental Management 90, 1195-1203.

Thierfelder, H., Kabisch, N., 2016. Viewpoint Berlin: Strategic urban development in Berlin - Challenges for future urban green space development. Environmental Science \& Policy 62, 120-122.

Thompson, I., 2013. Urban parks A history: 1839-2012. Landscape 2013.

Threlfall, C.G., Kendal, D., 2018. The distinct ecological and social roles that wild spaces play in urban ecosystems. Urban Forestry \& Urban Greening.

Ulrich, R.S., 1984. View through a window may influence recovery from surgery. Science 224, 420-421.

United Nations, 2015. World Urbanaization Prospects: The 2014 Revision. Department of Economic and Social Affairs, Population Division, New York.

United Nations, 2016. New Urban Agenda: Draft Resolution / Submitted by the President of the General Assembly. United Nations, New York.

United Nations, 2017. Goal 11: Make cities inclusive, safe, resilient and sustainable.

Urry, J., 1990. The Tourist Gaze: Leisure and Travel in Contemporary Societies. Sage, London.

Van den Berg, A.E., Jorgensen, A., Wilson, E.R., 2014. Evaluating restoration in urban green spaces: Does setting type make a difference? Landscape and Urban Planning 127, 173-181.

Voigt, A., Kabisch, N., Wurster, D., Haase, D., Breuste, J., 2014. Structural Diversity: A Multi-dimensional Approach to Assess Recreational Services in Urban Parks. AMBIO 43, 480-491.

Voigt, A., Wurster, D., 2015. Does diversity matter? The experience of urban nature's diversity: Case study and cultural concept. Ecosystem Services 12, 200-208.

Wendel, H.E.W., Zarger, R.K., Mihelcic, J.R., 2012. Accessibility and usability: Green space preferences, perceptions, and barriers in a rapidly urbanizing city in Latin America. Landscape and Urban Planning 107, 272-282.

Wolff, M., Haase, A., Haase, D., Kabisch, N., 2017. The impact of urban regrowth on the built environment. Urban Studies 54, 2683-2700.

Zhang, H., Chen, B., Sun, Z., Bao, Z., 2013. Landscape perception and recreation needs in urban green space in Fuyang, Hangzhou, China. Urban Forestry \& Urban Greening 12, 44-52. 

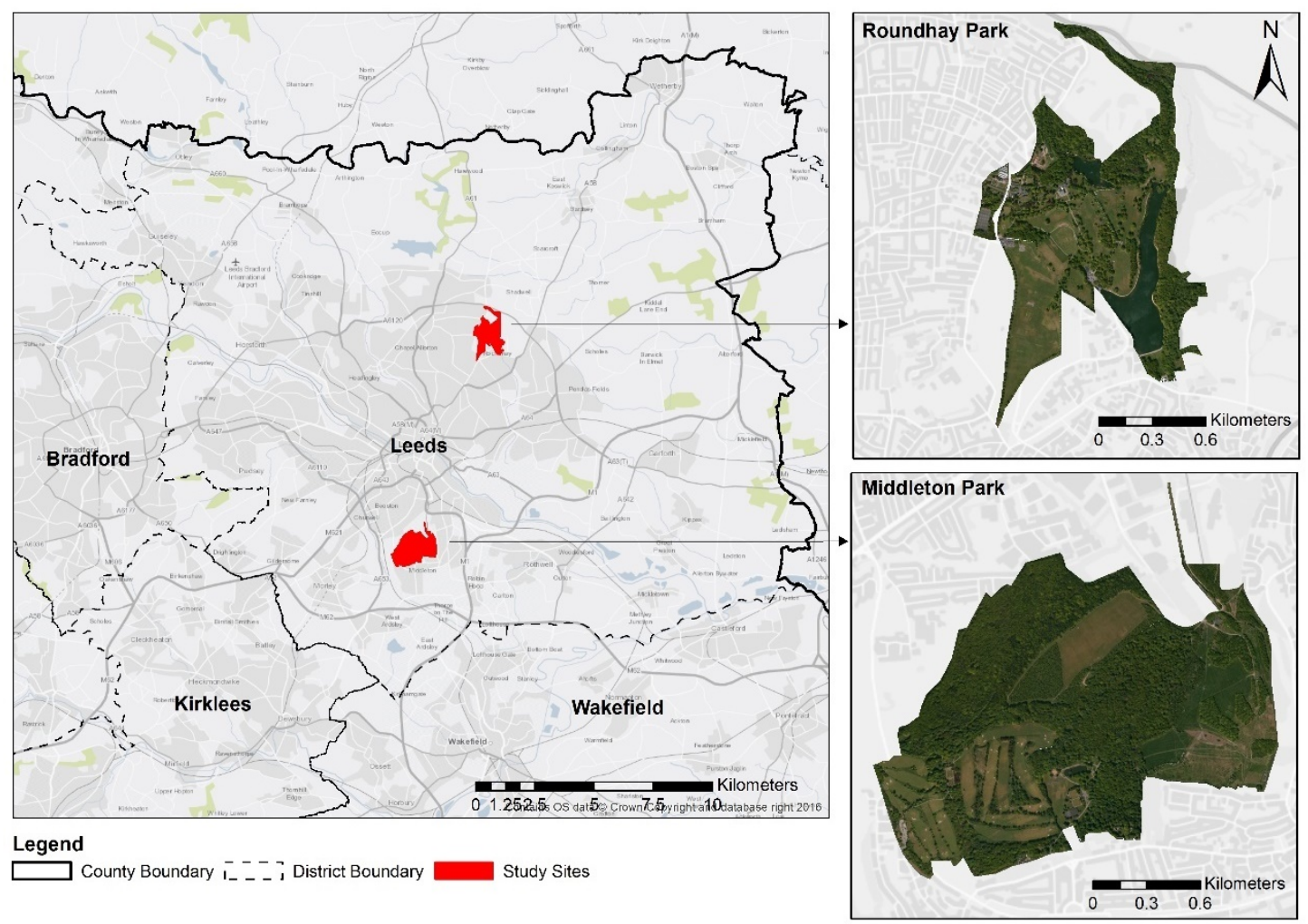

Figure 1. Study sites in Leeds
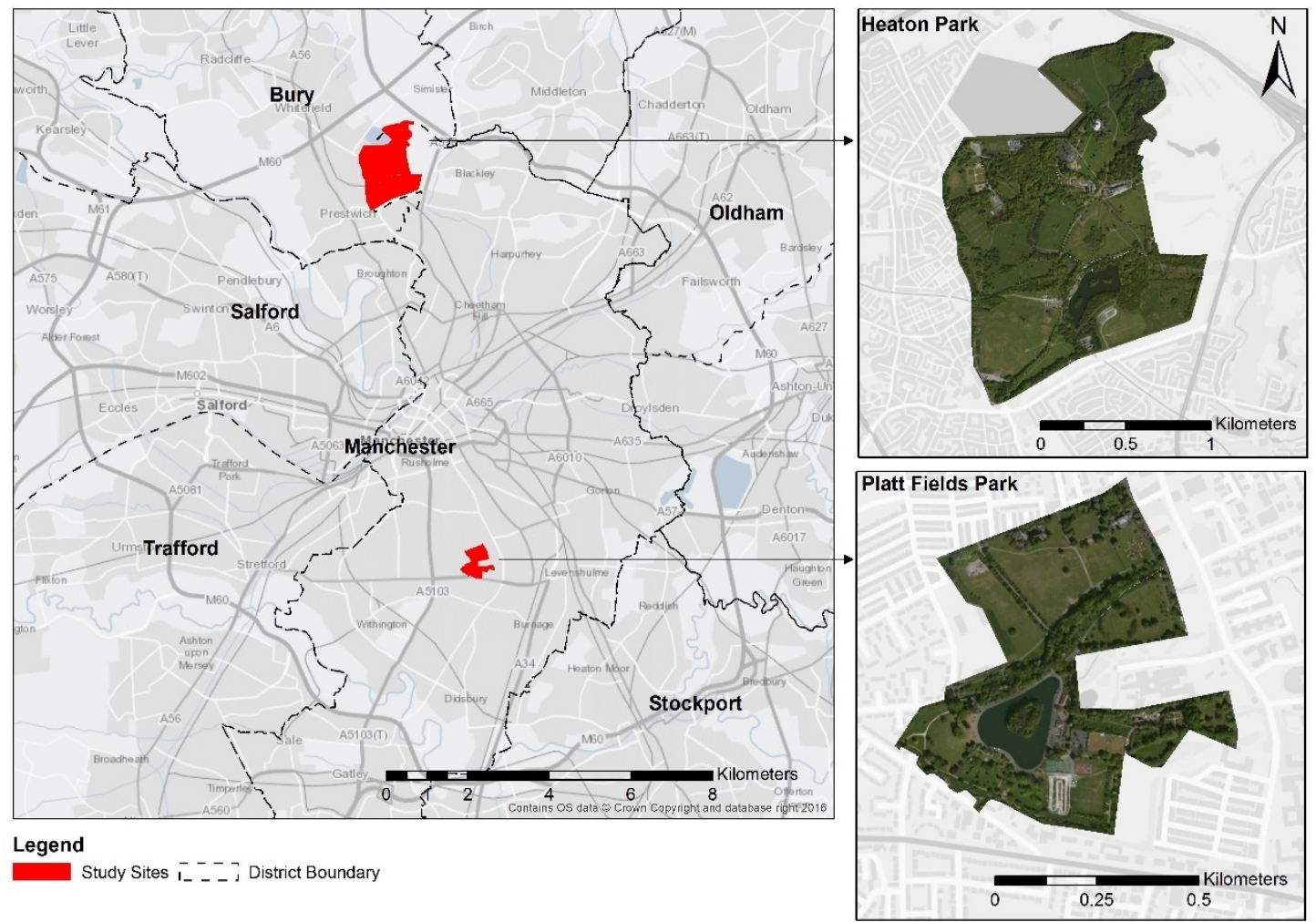

Figure 2. Study sites in Manchester 


\section{Preferences and perceptions}

\section{Users}

- Mixed UGSs preferred at highmedium tree densities

- Social elements like paths, benches and open spaces for comfort and accessibility

- Naturalness invoked sense of exploration and adventure

\section{Landscape professionals}

- Providing something for everyone or needs-based approach in smaller, budget constrained areas

- Smaller green spaces in urban core and larger ones further away

- Ideological shift from manicured/formal to mixed UGSs

User demand, knowledge and funding act as

Barriers/Opportunities

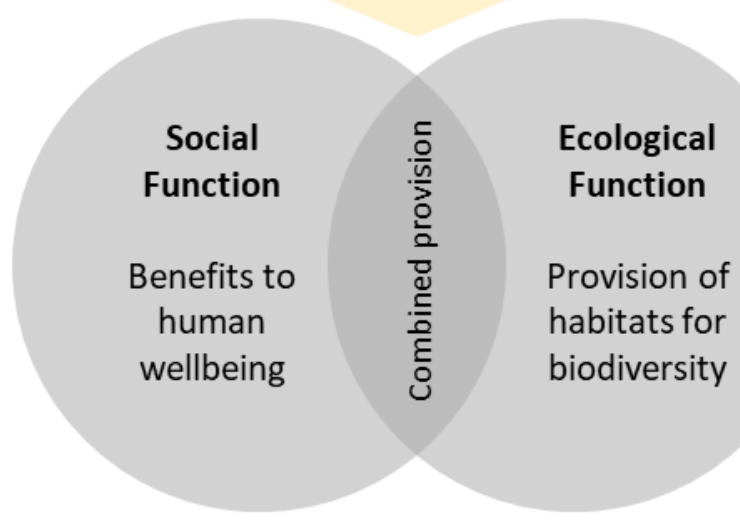

Urban Green Spaces

Figure 3. Summary of research findings 


\section{Table 1. Content of the user intercept questionnaire}

\begin{tabular}{|c|c|c|c|}
\hline Segment & Questions & & Response options \\
\hline $\begin{array}{l}\text { Profile } \\
\text { information }\end{array}$ & $\begin{array}{l}\text { - Age group } \\
\text { - Gender } \\
\text { - Ethnicity } \\
\text { - Education level } \\
\end{array}$ & & $\begin{array}{l}\text { These closed-ended questions had } \\
\text { multiple choices with different number } \\
\text { of choices and answer types }\end{array}$ \\
\hline Preferences & $\begin{array}{l}\text { UGS type visit frequency } \\
\text { - Urban parks } \\
\text { - Country parks/national parks } \\
\text { - } \text { Formal/botanical gardens } \\
\text { - Urban woodlands/forests } \\
\text { - Urban wetlands, canals, rivers } \\
\text { - Wilderness areas/nature reserves } \\
\text { - Derelict/unused open land } \\
\text { - Outdoor sports facilities/children's play areas } \\
\text { - Cemeteries and churchyards } \\
\text { - Small neighbourhood parks/green spaces in and around buildings } \\
\text { - Community gardens/urban farms } \\
\text { Purpose of UGS visit } \\
\text { - Getting fresh air/relaxing in nature } \\
\text { - Feeding birds/bird watching } \\
\text { - Dog walking } \\
\text { - Meditation/yoga } \\
\text { - Reading } \\
\text { - Sunbathing } \\
\text { - Walking } \\
\text { - Organised/unorganised sports } \\
\text { - Running/jogging/cycling/other exercise } \\
\text { - Playing with children/enjoying family time } \\
\text { - Attending an event } \\
\text { - General socialising } \\
\text { - Picnics/barbecue }\end{array}$ & $\begin{array}{l}\text { UGS characteristics } \\
\text { - Size } \\
\text { - Accessibility } \\
\text { - Nearness to residence } \\
\text { - Biodiversity } \\
\text { - Variation in the natural } \\
\text { landscape } \\
\text { - Manmade structures } \\
\text { - Safety } \\
\text { - Non-crowding } \\
\text { - Cleanliness } \\
\text { UGS facilities } \\
\text { - Cafes/restaurants } \\
\text { - Toilets } \\
\text { - Walking/cycling paths } \\
\text { - Benches for sitting } \\
\text { - Availability of parking areas } \\
\text { - No parking charges } \\
\text { - Playing areas for children } \\
\text { - Designated sporting areas } \\
\text { - Picnic/barbecue areas } \\
\text { - Signposting } \\
\text { - Updated information on } \\
\text { website }\end{array}$ & $\begin{array}{l}\text { Five-point Likert scale to rate } \\
\text { importance or frequency starting with } \\
\text { "not important" and ending with } \\
\text { "most important." Frequency of visit } \\
\text { options were "never", "once a year", } \\
\text { "few times a year", "once a month" } \\
\text { and "once a week or more." Open- } \\
\text { ended probing questions about } \\
\text { reasons behind the ratings were asked }\end{array}$ \\
\hline $\begin{array}{l}\text { Photo } \\
\text { Elicitation }\end{array}$ & (1) & ( & $\begin{array}{l}\text { Five-point Likert scale to rate } \\
\text { preference starting with "most } \\
\text { disliked" and ending with "most liked." } \\
\text { Open-ended probing questions about } \\
\text { reasons behind the ratings were asked. }\end{array}$ \\
\hline
\end{tabular}


Table 2. Profile of interviewed UGS users

\begin{tabular}{|c|c|c|c|c|c|c|c|c|}
\hline \multirow{2}{*}{\multicolumn{2}{|c|}{ Study Sites }} & \multicolumn{4}{|c|}{ Leeds } & \multicolumn{3}{|c|}{ Manchester } \\
\hline & & \multicolumn{2}{|c|}{ Roundhay Park } & \multicolumn{2}{|c|}{ Middleton Park } & \multicolumn{2}{|c|}{ Heaton Park } & \multirow{2}{*}{$\begin{array}{c}\text { Platt Fields } \\
\text { Park }\end{array}$} \\
\hline $\begin{array}{l}\text { Week } \\
\text { Wee }\end{array}$ & $\begin{array}{l}\text { end(WE)/ } \\
\text { day(WD) }\end{array}$ & $\begin{array}{c}\text { WE } \\
(n=30)\end{array}$ & $\begin{array}{c}\text { WD } \\
(n=10)\end{array}$ & $\begin{array}{c}\text { WE } \\
(n=30)\end{array}$ & $\begin{array}{c}\text { WD } \\
(n=10)\end{array}$ & $\begin{array}{c}\text { WE } \\
(n=30)\end{array}$ & $\begin{array}{c}\text { WD } \\
(n=10)\end{array}$ & \\
\hline \multicolumn{9}{|c|}{ Variables (\% of $\mathrm{n})$} \\
\hline \multirow{5}{*}{ Age } & $18-24$ & 17 & 70 & 3 & 20 & 0 & 20 & 10 \\
\hline & $25-34$ & 40 & 0 & 47 & 70 & 63 & 20 & 47 \\
\hline & $35-44$ & 20 & 0 & 40 & 0 & 27 & 0 & 30 \\
\hline & $45-54$ & 17 & 0 & 7 & 0 & 7 & 40 & 7 \\
\hline & $55-64$ & 7 & 30 & 3 & 10 & 3 & 20 & 7 \\
\hline \multirow{3}{*}{ Gender } & Female & 47 & 50 & 37 & 90 & 63 & 40 & 67 \\
\hline & Male & 53 & 50 & 63 & 10 & 37 & 60 & 33 \\
\hline & Other & 0 & 0 & 0 & 0 & 0 & 0 & 0 \\
\hline \multirow{4}{*}{ Ethnicity } & Asian & 10 & 10 & 7 & 0 & 20 & 10 & 7 \\
\hline & Black & 7 & 10 & 7 & 0 & 0 & 30 & 7 \\
\hline & White & 80 & 80 & 83 & 100 & 80 & 60 & 87 \\
\hline & Mixed & 3 & 0 & 3 & 0 & 0 & 0 & 0 \\
\hline \multirow{5}{*}{ Education } & Degree & 73 & 0 & 33 & 30 & 40 & 0 & 41 \\
\hline & $\begin{array}{l}\text { Below } \\
\text { degree }\end{array}$ & 13 & 30 & 20 & 20 & 10 & 10 & 15 \\
\hline & A' Level & 7 & 40 & 13 & 20 & 7 & 30 & 14 \\
\hline & Secondary & 7 & 10 & 10 & 10 & 33 & 50 & 18 \\
\hline & Primary & 0 & 20 & 23 & 20 & 10 & 10 & 12 \\
\hline
\end{tabular}

Table 3. Profile of interviewed key informants/ landscape professionals

\begin{tabular}{|c|c|c|c|c|}
\hline $\begin{array}{l}\text { Landscape } \\
\text { professional }\end{array}$ & Leeds & Manchester & Interviewee codes & Examples of roles and responsibilities \\
\hline $\begin{array}{l}\text { Regional } \\
\text { organisation } \\
\text { manager } \\
\end{array}$ & 0 & 2 & $\begin{array}{l}\text { REGIONAL A, } \\
\text { REGIONAL B }\end{array}$ & $\begin{array}{l}\text { Development of regional/county strategies; } \\
\text { Planning and delivery of key projects on the } \\
\text { ground through consultation with academics }\end{array}$ \\
\hline $\begin{array}{l}\text { Local } \\
\text { government } \\
\text { manager }\end{array}$ & 3 & 2 & $\begin{array}{l}\text { GOVERNMENT A, } \\
\text { GOVERNMENT B, } \\
\text { GOVERNMENT C, } \\
\text { GOVERNMENT D, } \\
\text { GOVERNMENT E, }\end{array}$ & $\begin{array}{l}\text { Management and governance of parks } \\
\text { within a district/borough; } \\
\text { Engaging with council teams, residents, } \\
\text { voluntary organisations and businesses to } \\
\text { development management and planning } \\
\text { strategies }\end{array}$ \\
\hline $\begin{array}{l}\text { Voluntary } \\
\text { organisation } \\
\text { manager }\end{array}$ & 3 & 0 & $\begin{array}{l}\text { VOLUNTARY A, } \\
\text { VOLUNTARY B, } \\
\text { VOLUNTARY C }\end{array}$ & $\begin{array}{l}\text { Undertaking general maintenance and } \\
\text { planting work in selected areas of } \\
\text { parkland, woodlands, streams or } \\
\text { footpaths; } \\
\text { Raising funds for new facilities; } \\
\text { Enhance visitors' enjoyment and knowledge } \\
\text { through booklets }\end{array}$ \\
\hline Academic & 1 & 1 & $\begin{array}{l}\text { ACADEMIC A, } \\
\text { ACADEMIC B }\end{array}$ & $\begin{array}{l}\text { Producing scientific knowledge through } \\
\text { research; } \\
\text { Collaborating with city councils for developing } \\
\text { planning strategies and targeted projects }\end{array}$ \\
\hline
\end{tabular}

